\title{
Islamic And Conventional Equity Indices: An Examination Of Cointegration And Hedging
}

Robert J. Boldin, Indiana University of Pennsylvania, USA Mukesh Chaudhry, Indiana University of Pennsylvania, USA Ibrahim Affaneh, Indiana University of Pennsylvania, USA

\begin{abstract}
Linkages between the Islamic Stock Indices, the Indices of Europe, Asia, US, UK, and Japan, and those of the emerging markets are empirically analyzed. Using methodologies that account for idiosyncratic factors in the data, evidence of linkages are found between large stock markets of Europe, Asia, US, and UK. Emerging markets indices show clear insulation from the Islamic indices. Although, emerging markets follow the Islamic based investment approach, other aspects such as economic factors as well as the size of the industry have dissimilarities. Hence, strategies for hedging or diversification, particularly in the long-run can be developed. If emerging market indices are combined with the indices of other markets, there may be considerable risk reduction with such a strategy.
\end{abstract}

Keywords: Islamic; Indices; Cointegration; Hedging

\section{INTRODUCTION}

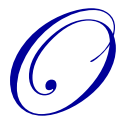

ver the last 12 years, there has been a proliferation of Islamic Investment Indices. By the end of 2010, more than 100 indices have been developed by several providers including Dow Jones, JP Morgan, Citigroup, MSCI, S\&P, FTSE, Ernest\& Young, and others. The leading provider is Dow Jones who developed the earliest index called Islamic Market World Index (DJIMWI) in 1999. By the end of 2010, Dow Jones developed more than 62 Global, Regional and Country Islamic investment indices. Five are sub-market regional indices and the rest are country indices. Every index is distributed among 10 sectors, the same as conventional indices but with different weights, primarily in the financial sector.

The main incentive behind developing these indices is to absorb the huge surplus of petrofunds accumulated by the oil exporting countries (OPEC), mostly Muslim countries. The indices are used in two ways. On one hand, they are used as a benchmark against which the performance of the Islamic Investments is measured and compared. On the other hand, they serve as an investment universe from which the Islamic portfolios and funds could be constructed and developed. The main distinction between the Islamic funds universe and the conventional funds universe is that the former has $7 \%$ invested in fixed income funds while the latter has $22 \%$ of their investment in fixed income funds (Ernest \& Young, 2010). This means that the Islamic Indices are skewed toward equity with extremely low investment in fixed income securities and in the financial sector. As a result of this narrower investment universe, the different distribution among sectors as compared to the more conventional indices can lead to the assumption that the Islamic indices are independent of conventional indices.

The purpose of this study is to investigate the linkages among the various Islamic Investment Indices and with the other non-Islamic conventional global and regional indices. This research examines the implications of constructing diversified portfolios in an effort to provide opportunities for cross-hedging. The next section describes the literature review. Section III discusses the research design; Section IV presents the data; Section V discusses the analysis and results; and, the last section presents the conclusions. 


\section{BRIEF MOTIVATION ON THE USE OF COINTEGRATION TECHNIQUES}

The literature notes that in order to effectively examine linkages between assets, one must account for idiosyncraticies in the data. Studies find the presence of nonstationarity (Chaudhry, Myer, \& Webb, 1997) and autocorrelation and nonnormality (Myer \& Webb, 1994) to be pervasive in time-series data. Consequently, standard statistical procedures, especially in the presence of nonstationarity, will likely give less-accurate inferences on linkages between time-series data. Recent advances in cointegration methodologies may help address this issue. Cointegration methods provide an alternative framework for investigating equilibrium price adjustments, particularly in time-series data that exhibit nonstationarity especially in their long-run relationships. Not surprisingly, there is evidence of nonstationarity in the data used in this study.

The literature indicates that nonstationarity is not a phenomenon limited to equity data. Cointegration has been applied to other data as well. For instance, Bradley and Lumpkin (1992) use cointegration methods to examine the relation between Treasury instruments. They find strong evidence of cointegration in seven Treasury rates. No less noteworthy is the application of cointegration methods in real estate studies (see e.g., Abeybayehu \& Kuchler, 1993; Rudolph \& Griffiths, 1997). Rudolph and Griffiths (1997) used cointegration analysis to test if many of the institutions formed in the secondary mortgage markets during the 1963-1993 period and the accompanying deregulation led to a closer relationship between the mortgage market and national capital markets. They also analyzed three sub-periods within this time frame. A cointegration type framework allowed them to conclude that the mortgage market and national capital markets were cointegrated over the entire period, as well as over subperiods.

Most of the studies of equity indices focus on measurements and comparison of their performance with that of conventional investments. Research has ignored the cointegration of these Islamic investments among themselves and with the conventional investments. Yet, this information can help in developing more diversified portfolios that can generate higher returns and lower risks and which can be used to hedge risks. The emergence of the Islamic Investment Funds and Indices led a few scholars to study this phenomenon. Some studies are descriptive such as that conducted by Wilson (1997) and Bose and McGee (2009). Others are empirical as conducted by Atta (2000) and Hassan \& Lewis (2007). The descriptive studies discussed the different types of Islamic faith, ethical and financial norms, and the developments of the Islamic financial institutions and products over the last two decades. The empirical studies focused on comparing the performance of Islamic Funds with that of Conventional Funds. They used the risk-adjusted return measurements by: Sharpe, Treynor, and Jenson's Alpha to compare the performances of the two investments. Interestingly, some studies concluded that Islamic funds performance was better than their conventional counterparts.

Socially Responsible Investing (SRI) was also subject to a wider investigation. For example, studies by Hamilton, Jo, and Statman (1993), Hoje, Saha, Sharma, and Wright (2010), and Hong and Kacperczyk (2009) provided mixed results. Some studies concluded that SRI outperformed the conventional indices, while others concluded that the Sin Investments outperformed the SRI. The most recent study by Hoje et al. (2010) concluded that, historically, sin based investments have performed better than SRI based investments over the long run, but not over the short run (one year). They attributed that to the assumption that socially responsible investors value social responsibility more than profitability over the long term. These mixed conclusions could provide evidence of the independence of the SRI including Islamic investments from the conventional indices.

\section{RESEARCH DESIGN}

While most time-series are non-stationary, the use of cointegrated methodologies can account for this characteristic $^{1}$ (see appendix for notes). Engle and Granger (1987) suggest that if a system of variables is

\footnotetext{
${ }^{1}$ A stochastic process is said to be stationary if the joint and conditional probability distribution of the process is invariant with respect to time. In practice, we set a less stringent standard for stationarity (weak form). We assume a process is stationary if the means and variances of the process are invariant with respect to time and the covariance between two periods is a function of the time interval between the two periods. Most time series are nonstationary. For instance, Nelson and Plosser (1982) find evidence consistent with the notion that microeconomic time series are better characterized as nonstationary processes that have no tendency to return to a deterministic path, but as stationary fluctuations around a deterministic trend. Brenner and Kroner (1995) also report the prevalence of stochastic trends in financial time series such as stock prices, foreign exchange rates, forward prices and future prices. They also note that the presence of trend limits the set of statistical models that can be used to implement financial theories.
} 
cointegrated, then economic forces interact to bind these variables together in a long-run equilibrium relationship. They suggest that an error correction model (ECM) can represent the cointegrated variables. ${ }^{2}$ In general, the ECM shows the dependence of this period's price change on the last period's price change, thus providing a measure of how far the system is out of its long-run equilibrium.

There are preliminaries a researcher has to observe before applying the methods of co- integration. Specifically, before testing for cointegration between two or more series, it is necessary to test whether the different time series are integrated to the same order. ${ }^{3}$ This is done by applying conventional unit roots tests, described below.

\section{A. Stationary (Unit Root) Tests for Individual Time Series}

In general, most texts on stationarity of a time series $\left(\mathrm{TS}_{\mathrm{t}}\right)$ will probably begin with estimation of the following regression equation, if no linear trend is considered.

$$
\Delta T S_{t}=\alpha_{0}+\alpha_{1} T S_{t-1}+\sum_{j=1}^{\rho} \gamma_{j} \Delta T S_{t-j}+\varepsilon_{t}
$$

and by Equation (2) when linear trend and a parameter for drift are considered:

$$
\Delta T S_{t}=\alpha_{0}+\alpha_{1} T S_{t-1}+\alpha_{2} t+\sum_{j=1}^{\rho} \gamma_{j} \Delta T S_{t-j}+\varepsilon_{t}
$$

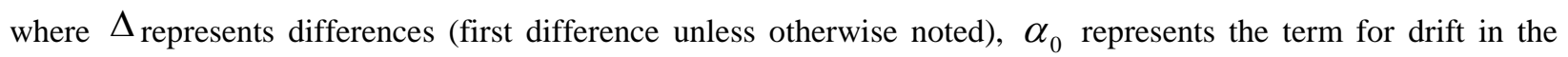
series, $\alpha_{1}$ allows testing for a unit root, and $\alpha_{2}$ verifies the presence of a trend. The error-correcting mechanism is represented by $\Delta T S_{t-j}$ in the model. If the hypothesis $\alpha_{1}=0$ cannot be rejected, then the series is said to have a unit root and is nonstationary. ${ }^{4}$ Conversely, if the hypothesis $\alpha_{1}=0$ is rejected, it is concluded that the series does not contain a unit root and is stationary. Tests involving parameters $\alpha_{0}$ and $\alpha_{2}$ verify the presence of drift and trend, respectively. Inclusion of the p lagged values ensures a white-noise series. The number of lags is determined by a test of significance, such as the Akaike information criterion (AIC) (Akaike, 1973). ${ }^{5}$ Importantly, the distribution of the ordinary $\mathrm{t}$ and $\mathrm{F}$ statistics computed for the regressions do not have their expected distribution. Thus, in order to test various hypotheses, critical values have been computed using Monte Carlo techniques and are tabulated in various references (Davidson \& MacKinnon, 1993). Tests for stationarity and cointegration use the

\footnotetext{
${ }^{2}$ The ECM has become quite popular and the use of such models is becoming more frequent. The basic idea behind the ECM is straightforward. Disequilibrium in one period is corrected in the next. For example, in a two-variable system a typical error correction model would relate the change in one variable to past equilibrium errors, as well as to past changes in both variables (Engle \& Granger, 1987). Most texts on cointegration provide an explanation of the ECM.

${ }^{3}$ Engle and Granger (1987), point out that a series will be integrated to order $\mathrm{d}(I(d))$ if, when differenced $d$ times, the series has a stationary, invertible, ARMA representation. A system consisting of two or more series is said to be cointegrated if the series making up the system are integrated of the same order, but some linear combination of the series in the system is integrated to a lower order.

${ }^{4}$ Manuals, such as handbooks on econometrics packages like EView, SHAZAM, and RATS, provide a quick background on cointegration tests and references to related theory. For more detailed discussions and background texts such as "New Directions in Econometric Practice" by Charemza and Deadman should be consulted.

${ }^{5}$ The use of the AIC to determine lag length is not universal. Other procedures are used such as the Schwarz Criterion. The Schwarz Criterion is more restrictive than the AIC and will always choose a model smaller than or equal to the AIC. Some determine the lag length by successively testing shorter lag lengths as restrictions against longer lag lengths until significance is obtained. This procedure, generally, uses likelihood ratio methods (Harris et al., 1995).
} 
Philips-Perron (P\&P) non-parametric testing procedure (Philips \& Perron, 1988). The P\&P procedure is used since the crucial iid error assumption is not needed. ${ }^{6}$

\section{B. Integration/Segmentation Tests}

This part of the analysis uses the methodology developed by Johansen (1988). It is preferred to alternatives since it enables testing for the presence of more than one cointegrating vector. The description that follows draws from Johansen (1988, 1991, 1994) and Johansen and Juselius (1990, 1991).

The Johansen method provides some distinct advantages. For example, identification of the number of cointegrating vectors is possible with the Johansen test. Such inferences are based on the number of significant eigenvalues. Also, many argue that the statistical properties and power for Johansen's test are generally higher than for alternative procedures. To check for stationarity arising from a linear combination of variables, the following AR representation for a vector VTS made up of $\mathrm{n}$ variables is used,

$$
V T S_{t}=c+\sum_{i=1}^{s-1} \phi_{i} Q_{i t}+\sum_{i=1}^{k} \pi_{i} V T S_{t-i}+\varepsilon_{t}
$$

where VTS is at most I(1), Qit are seasonal dummies (i.e., a vector of non-stochastic variables) and c is a constant. It is not necessary that all variables that make up VTS be I(1). To find cointegration in the system, only two variables in the system need be I(1). If only two time series are examined (bivariate representation), however, then both have to be I(1). If an error-correction term is appended, then:

$$
\Delta V T S_{t}=c+\sum_{i=1}^{s-1} \phi_{i} Q_{i t}+\sum_{i=1}^{k-1} \Gamma_{I} \Delta V T S_{t-i}+\Pi V T S_{t-k}+\varepsilon_{t}
$$

which is basically a vector representation of Equation (1) with seasonal dummies added. All long-run information is contained in the levels terms, $\Pi V T S_{t-k}$, and short-run information in the differences $\Delta V T S_{t-i}$. The above equation would have the same degree of integration on both sides only if $\Pi=0$ (the series are not co integrated) or $\Pi V T S_{t-k}$ is (0), which infers cointegration. In order to test for cointegration, the validity of H1(r), shown below, is tested as:

$$
H_{1}(r): \prod=\gamma \beta^{\prime}
$$

where $\beta$ is a matrix of co integrating vectors and $\gamma$ represents a matrix of error correction coefficients. The hypothesis $\mathrm{H} 1(\mathrm{r})$ implies that the process $\Delta V T S_{t}$ is stationary, VTSt is nonstationary, and $\beta^{\prime} \mathrm{VTS}_{\mathrm{t}}$ is stationary (Johansen, 1991). The Johansen method yields the Trace and the $\lambda_{\max }$ statistics that enable determination of the number of cointegrating vectors.

\section{DESCRIPTION OF DATA}

The monthly data of Islamic Indices used in this study were obtained from Bloomberg. The sample spans the period January 2004 through October 2008. One important issue regarding the data was addressed. The use of

\footnotetext{
${ }^{6} \mathrm{P} \& \mathrm{P}$ impose only weak restrictions on the error sequence; thus, this test is considered robust to a variety of heterogeneously distributed and weakly dependent innovations since P\&P correct the standard errors used to compute $t$ values using the Newey and West (1987) correction.
} 
monthly data, and the lesser frequency of observations versus the use of weekly or daily data, may create misgivings about the power of unit-root and cointegration tests against an alternative hypothesis, such as a trend stationary model. ${ }^{7}$ Hakkio and Rush (1991), from Monte Carlo simulations, however, showed that the frequency of information plays a minor role; rather, it is the length of data series or span, which is more important in discerning whether the time series are co integrated or not. This finding is also supported by Shiller and Perron (1985) and Perron (1989) who found that changing the frequency of observations, while keeping the sample length fixed, is not helpful when testing for cointegration because it is mainly a long-run phenomenon. The Conventional Dow Jones World Index (DJWI) has 6229 components while the Islamic Index (DJIMI) has 2343 components or 37.6\% of the DJWI at the end of 2009; the industry allocation is considerably different, most notably in the financial industry as shown in Table 1.

Table 1: Regional versus World versus Industry Allocation

\begin{tabular}{|c|c|c|}
\hline Region & DJIMI & DJWI \\
\hline America & $64.59 \%$ & $52.62 \%$ \\
\hline Europe & $21.33 \%$ & $26.79 \%$ \\
\hline Asia/Pacific & $13.02 \%$ & $19.61 \%$ \\
\hline Number 2 Components & $37.60 \%$ & 6229 \\
\hline Industry & DJIMI & DJWI \\
\hline Basic Materials & $8.72 \%$ & $5.64 \%$ \\
\hline Consumer Goods & $9.57 \%$ & $10.53 \%$ \\
\hline Consumer Services & $7.52 \%$ & $10.69 \%$ \\
\hline Financials & $0.65 \%$ & $24.95 \%$ \\
\hline Health Care & $20.36 \%$ & $9.17 \%$ \\
\hline Industrials & $10.29 \%$ & $12.38 \%$ \\
\hline Oil and Gas & $18.04 \%$ & $8.62 \%$ \\
\hline Technology & $20.02 \%$ & $9.86 \%$ \\
\hline Telecommunications & $4.05 \%$ & $4.19 \%$ \\
\hline Utilities & $0.79 \%$ & $3.97 \%$ \\
\hline
\end{tabular}

In addition, the figures in Table 1 indicate that the DJIMI Index is highly concentrated in the Americas, mainly the U.S., while the DJWI is more diversified among the three regions. More than 50\% of the DJIMI Index is concentrated in the three industries (Health Care, Technology, and Oil and Gas) while the DJWI is more diversified with more allocation to the financial industry. This is a result of avoiding financial dealings with interest rates which is illegal in the Islamic Shariah Law.

The exclusion of the interest-bearing assets from Islamic investment could lead to the loss of substantial income that is usually generated by the conventional investments from interest income. The loss of additional income could lead to lower market prices of Islamic Compatible Companies which would lower the return on Islamic Indices. In addition the figures indicate that the financial sector, which relies heavily on interest generated income, is only $.65 \%$ in the DJIMI while it is $24.95 \%$ in the DJWI. Again these figures could provide an additional evidence that Islamic Indices are independent of the Conventional Indices.

\section{EMPIRICAL TESTS AND RESULTS}

\section{A. Tests for Stationarity of Each Time Series Using the Philips-Perron (P\&P) Test}

The time series are tested for a unit root using the P\&P tests. The P\&P tests suggest that all of the time series are nonstationary without trend (i.e., non-rejection of $\alpha_{1}=0$ ). In most instances with trend, there is a clear indication of the need for cointegrated methodologies (critical values at the $10 \%$ level are provided in the last row of Table 2). While it is reassuring to note the non-rejection of nonstationarity, this is not altogether surprising since many other studies find nonstationary in time series (Phillips \& Perron, 1988; Brenner \& Kroner, 1995).

\footnotetext{
${ }^{7}$ TDI's data base is compiled from official exchange time and sales record and any missing data points are filled with data from various real time data feeds. Monthly prices are used to construct the time-series for each future and the expiring futures contract is rolled over into the next-toexpire contract on the first day of the expiration month.
} 
Table 2: Tests of Stationarity for the Islamic Equity Indices of Countries/Regions (P\&P)

\begin{tabular}{|l|c|c|c|}
\hline \multicolumn{1}{|c|}{ Series } & Nlags & $\begin{array}{c}\text { No Trend } \\
\boldsymbol{\alpha}_{\mathbf{1}}=\mathbf{0}\end{array}$ & $\begin{array}{c}\text { Akaike Criterion } \\
\text { (minimized) }\end{array}$ \\
\hline Country Index/Region/World Islamic Indices & -1.79 & 11.36 \\
\hline Asia & 3 & -1.79 & 11.13 \\
\hline Asia Large & 4 & -1.74 & 10.79 \\
\hline Developed World & 5 & -1.50 & 13.48 \\
\hline Large Europe & 5 & -1.23 & 10.67 \\
\hline Japan & 4 & -1.68 & 11.78 \\
\hline UK & 3 & -1.70 & 11.73 \\
\hline US & 2 & -1.64 & 12.58 \\
\hline US Large & 1 & -1.85 & \\
\hline Emerging Markets & 4 & & \\
\hline Asymptotic Critical Values & \multicolumn{3}{|}{} \\
\hline 10\% Level & -2.57 & & \\
\hline 5\% Level & -2.90 & & \\
\hline 1\% Level & -3.53 & & \\
\hline
\end{tabular}

The P\&P denotes the Phillips-Perron tests. P\&P is computed with a constant term. The tests are conducted with and without linear trend. The Unit Root tests are performed with the appropriate lag length. For each time series the lag length are estimated by minimizing the Akaike Information Criterion (AIC) values. T-Values (single hypothesis) and F-values (multiple hypotheses) for tests of various hypotheses concerning equation no trend and equation with trend are estimated. Note, $\alpha 1=0$ is the unit root test, $\alpha 0=0$ tests for constant (drift), and $\alpha 2=0$ tests for linear trend. Asymptotic critical values are from Phillips and Perron (1986).

\section{B. Johansen Tests for Co Integration Rank for System of Equity Markets}

Results for the selected equity indices using Johansen's method are presented in Table 3. The tests using Trace statistic are reported along with the critical and the ' $p$ ' values. These are basically likelihood ratio tests where the null hypothesis is $\mathrm{L}_{\mathrm{r}+1}=\mathrm{L}_{\mathrm{r}+2}=\ldots \ldots .=\mathrm{L}_{\mathrm{p}}=0$, indicating that the system has $p$ - $r$ unit roots, where $r$ is the number of cointegrating vectors. The rank is then determined using a sequential approach starting with the hypothesis of $p$ unit roots. If this is rejected then the next hypothesis $\mathrm{L}_{2}=\mathrm{L}_{3}=\ldots \ldots=\mathrm{L}_{\mathrm{p}}=0$ is tested and so on. ${ }^{8}$

Table 3: Long-Term Relationship between the Islamic Equity Indices of Countries/Regions Using Johansen's Cointegration Methodology

\begin{tabular}{|c|c|c|c|c|}
\hline Group & $\mathbf{r}$ & Trace & 5\% Critical Value & Prob. \\
\hline \multirow{2}{*}{ Developed World and Emerging Markets } & 0 & 6.40 & 15.49 & 0.65 \\
\hline & 1 & 0.56 & 3.84 & 0.46 \\
\hline \multirow{3}{*}{ Large Stocks Indices (Europe, Asia, and US) } & 0 & $31.43^{* * *}$ & 29.80 & 0.03 \\
\hline & 1 & $14.91^{*}$ & 15.49 & 0.06 \\
\hline & 2 & 3.16 & 3.84 & 0.11 \\
\hline \multirow{2}{*}{ US Large and Asia Large } & 0 & $18.96^{* * * *}$ & 15.49 & 0.01 \\
\hline & 1 & $6.88^{* * *}$ & 3.84 & 0.00 \\
\hline \multirow{2}{*}{ Euro Large and Asia Large } & 0 & $18.86^{* * * *}$ & 15.49 & 0.01 \\
\hline & 1 & $4.51^{* *}$ & 3.84 & 0.03 \\
\hline \multirow{2}{*}{ Asia and UK } & 0 & $15.30^{* * *}$ & 15.49 & 0.05 \\
\hline & 1 & $4.84^{* *}$ & 3.84 & 0.03 \\
\hline \multirow{2}{*}{ Asia and US } & 0 & $21.74^{\text {**** }}$ & 15.49 & 0.00 \\
\hline & 1 & $8.06^{* * *}$ & 3.84 & 0.00 \\
\hline
\end{tabular}

The optimal lag length for Johansen co integration model is obtained from an examination of the residual autocorrelation functions of the co integrating regressions. Critical values for Johansen tests are taken from tables in Johansen and Juselius (1990) paper. The ***, **, * denotes significance levels of 1 percent, 5 percent, and 10 percent respectively.

From Table 3, it is evident that there is no cointegrating relationship between the developed market and the Emerging Market Islamic Indices. This result may be expected as these markets have different dynamics and levels of development. In fact, the emerging markets are substantially dependent upon oil which may have a negative correlation with the economies of the developed markets. For instance, when the oil prices are high, it may benefit the emerging markets Islamic indices at the expense of the developed market indices. In the other systems such as

\footnotetext{
${ }^{8}$ For a detailed discussion of both tests the reader is referred to Johansen and Juselius (1990) and Johansen (1988, 1991, 1994).
} 
Large Islamic stock Indices for Europe, Asia, and the US there are at least two cointegrating vectors. Similar relationships are found for US large with Asia Large, Asia, and UK, and Asia and the US. This implies that there are some fundamental factors that are binding the Islamic stock indices between US/Europe/Asia. It may be that these indices are comprised of similar industries that comply with the Islamic law and most of these indices have very low percentage of companies from the financial sector. Hence, there seems to be considerable commonality between these indices as the economic factors are likely to have similar effects on these companies.

In order to consider hedging possibilities, the relationship between equity markets with other markets or instruments of different countries within the Islamic Indices of different countries can be analyzed. Trace Values are shown for the full range of cointegrating vectors (i.e., for $n-1$ vectors). The rejection of $r=1$ indicates the presence of at least two cointegrating vectors and so on. It is evident that there are potential hedging candidates between the different indices. For instance, the conventional Dow Jones World Index is heavily skewed in favor of the financial sector whereas the Islamic Market world index is invested in technology, oil and gas, industrial, and consumer goods sectors. This may create greater portfolio diversification possibilities for the investors. It may be noted that Islamic indices of the Asia/Pacific region do tend to have Islamic financial institutions but their inclusion may not change the fundamental aspects of these indices as the Islamic financial institutions in this region have greater experience in their ability to comply with the Islamic law.

\section{Granger Causality Results}

Another relevant aspect is to determine which Islamic fund dominates in this group of equity markets. Hence, a bi-variate Granger causality test, reported in the Table 4, was conducted. From the results, it is evident, that in most cases, the null hypothesis that there is no causality between the equity markets of these sectors cannot be rejected. There is a bi-directional causality between US and Asia/Pacific regional index. A similar result is found between European and the Asian Large companies indices. The results conform very well with what is found in Table 3 where a clear cointegrating relationship is found between these Islamic Indices. As stated earlier, these sectors have some commonalities which is binding these indices in a bi-directional sense. As expected, the Islamic indices of emerging markets do not have any causal relationship with the other markets. On the other hand, US Islamic indices dominate other sectors such as the Islamic indices of Japan and the US.

Table 4: Pairwise Causality Tests for the Islamic Equity Indices of Countries/Regions

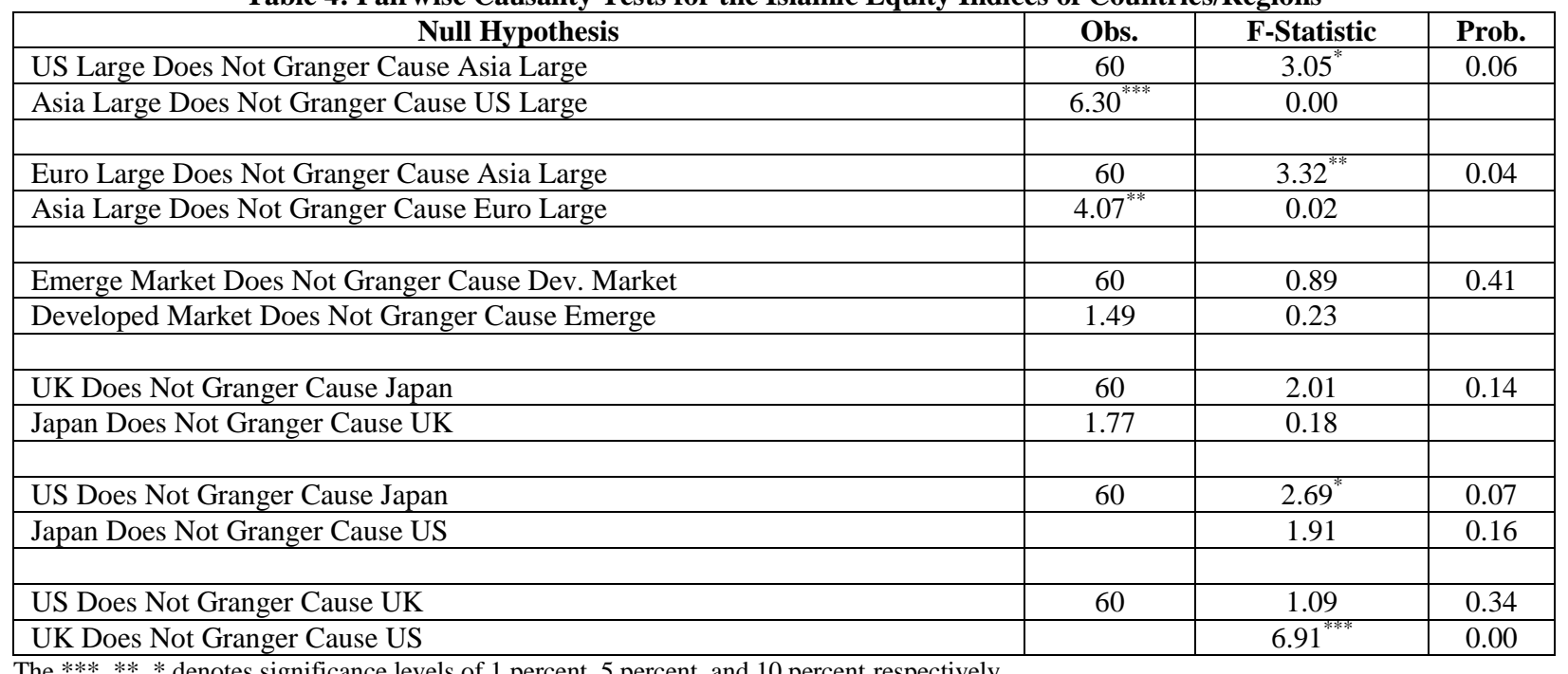

The ***, **, * denotes significance levels of 1 percent, 5 percent, and 10 percent respectively.

\section{CONCLUSION}

Most of studies related to these indices focus on measurements and comparison of performance with that of the conventional investments. Research which has been done tended to ignore the cointegration of these Islamic investments among themselves and with the conventional investments. But, diversified portfolios can be developed 
which should generate higher returns and lower risk, and which can be used to hedge risk. From this research, it is evident that the sectors that have commonalities, such as similarities in industries and the size of the companies, show cointegrating relationships. Indices of markets such as the large stocks of Europe, Asia, and the US are bound together in a long-term relationship. Also, these indices display a bi-directional causality which provides additional evidence of the closeness of this relationship. Common types of industries, similarities in economic factors, and the fact that these are Islamic indices with a similar Islamic based investment approach make it very likely that they would have similar co-movements. But, emerging markets indices show a clear insulation from the Islamic indices of the other markets. While emerging markets follow the Islamic based investment approach, other influences such as economic factors and size of industry cause dissimilarities. This result is also evident based on the Granger causality test where emerging markets do not display any causality with the Islamic indices of the other markets. For future research, it may be pertinent to examine the relationship between Islamic indices and bond yields for diversification purposes.

\section{AUTHOR INFORMATION}

Robert J. Boldin, Indiana University of Pennsylvania, Department of Finance and Legal Studies, Indiana, PA. 15705 (USA). E-mail: rboldin@iup.edu (Corresponding author)

Mukesh Chaudhry, Indiana University of Pennsylvania, Department of Finance and Legal Studies, Indiana, PA. 15705 (USA). E-mail: chaudhry@iup.edu

Ibrahim Affaneh, Indiana University of Pennsylvania, Department of Finance and Legal Studies, Indiana, PA. 15705 (USA). E-mail: affaneh@iup.edu

\section{REFERENCES}

1. Abebayehu,T., \& Kuchler, F. R. (1993). Evidence on the existence of speculative bubbles in farmland prices. Journal of Real Estate Finance and Economics, 6(3), 223-236.

2. Akike, H. (1973). Information theory and an extension of the maximum likelihood principle. In: B. N. Petrov \& F. Csaki (eds.), Second international symposium on information theory (pp. 267-281). Budapest: Akademiai Kiado.

3. Atta, H. (2000). Ethical rewards: An examination of the effect of Islamic ethical screens on financial performance and of conditioning information on performance measures. (Master of Science Dissertation). University of Durham.

4. Bose, S., \& McGee, R. (2009). Islamic investment funds: A analysis of risks and returns. International Journal of Business, Accounting and Finance, 3(2), 111-126.

5. Brenner, R. J., \& Kroner, K. F. (1995). Arbitrage, cointegration, and testing the unbiasedness hypothesis in financial markets. Journal of Financial and Quantitative Analysis, 30(1), 23-42.

6. Chaudhry, M. K., Myer, F. C. N., \& Webb, J. R. (1999). Stationarity and cointegration in systems with real estate and financial assets. Journal of Real Estate Finance and Economics, 18(3, May), 339-349.

7. Davidson, R., \& MacKinnon, J. G. (1993). Estimation and inference in economics. Oxford University Press.

8. Engle, R. F., \& Granger C. W. J. (1987). Co-integration and error correction: Representation, estimation, and testing. Econometrica, 55, 251-276.

9. Hakkio, C. S., \& Rush, M. (1991). Cointegration: How short is the long run? Journal of International Money and Finance, 10(4), 571-581.

10. Hamilton, S., Jo, H. \& Statman, M. (1993). Doing well while doing good? The investment performance of socially responsible mutual funds. Financial Analysts Journal 49(6, November-December), 62-66.

11. Harris, F. deB., McInish, T. H., Shoesmith, G. L. \& Wood, R. A. (1995). Cointegration, error correction, and price discovery on informationally linked security markets. Journal of Financial and Quantitative Analysis, 30(4), 563-579.

12. Hoje, J., Sharma, R., Wright, S., \& Saha, T. (2010) The performance of socially responsible investing vs. vice investing. Journal of Business Ethics. 
13. Hong, H., \& Kacperczyk, M. (2009). The price of sin: The effects of social norms on markets. Journal of Financial Economics, 93, 15-36.

14. Johansen, S. (1988). Statistical analysis of cointegration vectors. Journal of Economic Dynamics and Control, 12(2/3), 231-254.

15. Johansen, S. (1991). Estimation and hypothesis testing of cointegration vectors in gaussian vector autoregressive models. Econometrica, 59(6), 1551-1580.

16. Johansen, S. (1994). The role of the constant term in the cointegration analysis of non-stationary variables. Econometric Reviews, 13, 205-219.

17. Johansen, S., \& Juselius, K. (1990). Maximum likelihood estimation and inference on cointegration - with applications to the demand for money. Oxford Bulletin of Economics and Statistics, 52(2), 169-21.

18. Kabir Hassan, M., \& Lewis, M. K. (2007) A system at the crossroads. Thunderbird International Business Review, 49(3).

19. Myer, F. C. N., \& Webb, J. R. (1994). Statistical properties of returns: Financial assets versus commercial real estate. Journal of Real Estate Finance and Economics, 8(3), 267-282.

20. Nelson, C. R., \& Plosser, C. I. (1982). Trends and random walks in macroeconomic time series: Some evidence and implications. Journal of Monetary Economics, 10(2), 139-162.

21. Newey, W. K., \& West, K. D. (1987). A simple, positive semi-definite, heteroskedasticity and autocorrelation consistent covariance matrix. Econometrica, 55(3), 703-708.

22. Perron, P. (1989). Testing for a random walk - a simulation experiment of power when the sampling interval is varied. Advances in Econometrics and Modeling. Kluwer Academic Publishers.

23. Phillips, P. C. B., \& Perron, P. (1988). Testing for a unit root in time series regression. Biometrica, 75, 33546.

24. Rudolph, P. M., \& Griffiths, J. (1997). Integration of the mortgage market into the national capital markets: 1963-1993. Journal of Housing Economics, 6, 164-183.

25. Shiller, R. J., \& Perron, P. (1985). Testing the random walk hypothesis: Power versus frequency of observation. Economic Letters, 18, 381-386.

26. Wilson, R. (1997). Islamic finance and ethical investment. International Journal of Social Economics, 24(11). 
NOTES 